\title{
Editorial
}

\section{Brazilian scientific journals must be professionalized}

\author{
Cid Aimbiré M. Santos
}

Editor-in-chief

In the last editorial of 2012 (Perspectives for 2013, Vol. 22 No. 2) I wrote that it is important for Brazilian scientific journals to reach international visibility, and that Brazilian scientists should prioritize submitting their best manuscripts to Brazilian journals so that we can grow internationally. Beyond this recommendation, there are other factors that I would like to highlight the specific situation of the Brazilian Journal of Pharmacognosy that may also reflect important issues for other Brazilian scientific journals.

It is necessary and important that Brazilian agencies start thinking of new ways to encourage the professionalization of our journals. In general, scientific journals in Brazil do not have administrative structures that assist their growth. They are typically published by national scientific societies, or prestigious universities, but do not have employees or even their own headquarters. In most journals, the Editor-in-chief is a kind of one-manband, doing everything from receiving submissions to taking boxes to the post office. Moreover, this person is usually a university professor whose other responsibilities include classes, research, student supervision, and the responsibility to produce publications, in addition to serving as the editor of a scientific journal. In pursuit of international recognition, Brazil urgently needs to change this picture. We have about three to four thousand journals, and others are coming; however, we do not need more journals, we need to consolidate the best journals we have, especially those indexed in the ISI. To do so, the funding agencies need to think about professionalization.

The program that finances Brazilian periodicals from $\mathrm{CAPES} / \mathrm{CNPq} / \mathrm{MCT}$ is very important for maintaining the journals, but the resources are still insufficient. Only about $0.5 \%$ of research funding is intended to support the journals. In the case of the Brazilian Journal of Pharmacognosy, the funds we received for 2013 do not cover the costs of editing and graphic printing. Approximately $1 / 3$ of the total annual cost is paid by the Brazilian Society of Pharmacognosy.

We believe that three factors are important in assessing whether a journal should be professionalized: journals that publish only articles in the English language, journals that have an efficient system to manage the flow of submissions, and those that use strict criteria to evaluate submissions in order to publish the best articles. These factors are very important and must be taken into account in the distribution of resources by CAPES/CNPq/MCT publishing programs. These journals have demonstrated an interest in giving international visibility to the articles they publish, and therefore, they must hire publishers in order to grow. These professionals will control the flow of the journal more efficiently, maintaining an active review process, corresponding more effectively with authors and making the act of submission more pleasant.

As a result, the editor and the Editorial Board could direct their attention to more appropriate tasks such as defining new policies and new goals for the journal, from determining whether a submitted manuscript is appropriate for the journal to designing special issues or seeking out new subjects and new authors, widening the scope of the journal.

The Brazilian Journal of Pharmacognosy is aware of this challenge, and seeks to intensify this discussion with other entities looking to grow and increase their visibility abroad. 